\title{
Zinc Oxide Chemical Bath Deposition on Functionalized Organic Thin Films: Formation of
}

\section{Nanorods, Nanorockets and Nanoflowers}

Zhiwei Shi and Amy V. Walker ${ }^{1}$

Department of Materials Science Engineering, RL10, University of Texas at Dallas, 800 W. Campbell

Rd, Richardson TX 75080

Abstract: Controlling the morphology of nanostructured materials is critical for their use in technological applications including in sensing, electronics and energy harvesting. In this paper we investigate the reaction pathways involved and their dependence on reactant concentrations in the formation of $\mathrm{ZnO}$ nanomaterials on - $\mathrm{COOH}$ terminated self-assembled monolayers using a simple chemical bath deposition process which employs zinc acetate, which acts as the Zn source, and ethylenediamine, which acts as both the $\mathrm{O}$ source and a complexing agent for $\mathrm{Zn}^{2+}$. At a deposition temperature of $318 \mathrm{~K}\left(45^{\circ} \mathrm{C}\right)$ our data shows that the concentration of $\mathrm{Zn}^{2+}$ as well as the deposition bath $\mathrm{pH}$, which is controlled by the ethylenediamine concentration, is critical in determining the $\mathrm{ZnO}$ morphology. Above $0.01 \mathrm{M}$ zinc acetate at low bath $\mathrm{pH}(\sim 7.7-8.5)$, nanorods and nanorockets are observed to form. The nanorods exhibit a clear interface in the middle indicating that they are composed of two crystals. At lower zinc acetate concentrations over a wide $\mathrm{pH}$ range $(\sim 8.0-10.5)$ nanoflowers form. The nanorockets and nanoflowers grow via a modified La Mer mechanism in which there are multiple nucleation and crystallization steps. The initial nuclei are sphelurites (nanoflowers) or nanocrystallites (nanorockets). Since the reagent concentrations limit the reaction, for these initial precursor crystallites to increase in size, it is required dissolution and re-precipitation must occur. Thus at later times nanorockets or nanoflowers develop.

Keywords: zinc oxide, chemical bath deposition, organic thin films

\footnotetext{
${ }^{1}$ Corresponding Author: Email: amy.walker@utdallas.edu; Ph: +1 972883 5780; Fax: +1 9728835725. Page 1
} 


\section{Introduction}

Nanostructured films exhibit a wide range of novel electrical, chemical, optical and mechanical properties which result from surface and quantum confinement effects [1-3]. Such films have potential applications in areas including sensing [1, 3-5], energy conversion[6, 7] and electronics $[1,5]$. Gas phase reactions are often employed to prepare nanostructured films $[1,2,5]$. However, these methods are expensive and incompatible with some substrates because they require high temperatures (>773 K) and are performed in vacuo. An attractive alternative approach is to employ aqueous deposition methods, such as chemical bath deposition (CBD). These techniques generally be performed at low temperatures $(\leq 323 \mathrm{~K})$ and do not require the use of expensive vacuum equipment $[8,9]$.

To date most solution-based synthesis methods have produced films of nanorods, nanotubes or nanoflowers with or without the use of organic modifiers [3, 4, 10-12]. However, the pathways for transformation and formation of these nanomaterial morphologies are often poorly understood. Zinc oxide, which is an important II-VI semiconductor, has been synthesized from aqueous solutions with morphologies including hexagonal rods [12-15], star-like crystals [9, 15, 16], nanoflowers [10, 17, 18], nanoplates [9, 14, 17], ellipsoids [18], nanoneedles [15, 16] nanotubes [3] and even smooth films [10]. Further it is well known that the chemical, optical and electrical properties of $\mathrm{ZnO}$ are critically dependent upon the film surface area and microstructure $[1,6,19-21]$. It is therefore crucial to have precise control over these variables in designing $\mathrm{ZnO}$ based systems for practical applications. In general the growth kinetics of $\mathrm{ZnO}$ nanostructured films are described using growth-dissolution-recrystallization. However, the analysis is complicated by the use of different complexing agents [15, 22], organic additives [12] and experimental conditions such as deposition temperature $[15,16]$ and the application of ultrasound [10].

In this paper we systematically investigate how the morphologies of $\mathrm{ZnO}$ crystallites vary with reactant concentrations in a simple CBD process using zinc acetate and ethylenediamine on 
- $\mathrm{COOH}$ terminated self-assembled monolayers (SAMs) at a deposition temperature of $318 \mathrm{~K}$. In CBD a controlled ion-exchange precipitation reaction is used to deposit a thin film [8]. The reaction rate is generally controlled by the concentration of the "free" metal ion, which here is $\mathrm{Zn}^{2+}$. In this deposition, ethylenediamine (en) has two roles. First, ethylenediamine hydrolysis leads to an increase of $\mathrm{pH}$ and thus $\mathrm{OH}^{-}$concentration. This leads to a critical concentration of $\mathrm{OH}^{-}$ions and precipitation of $\mathrm{ZnO}$. In the plating solution:

$\mathrm{NH}_{2}\left(\mathrm{CH}_{2}\right)_{2} \mathrm{NH}_{2}+2 \mathrm{H}_{2} \mathrm{O} \leftrightharpoons\left[\mathrm{NH}_{3}\left(\mathrm{CH}_{2}\right)_{2} \mathrm{NH}_{3}\right]^{2+}+2 \mathrm{OH}^{-}$

The ethylenediamine also acts as a complexing agent for $\mathrm{Zn}^{2+}$ ions. Under our reaction conditions, previous studies indicate that dominant species present in the solution are $\mathrm{Zn}(\mathrm{en})_{\mathrm{x}}{ }^{2+}(\mathrm{x}=1-3)$ [23]. Once the solubility product $\left(\mathrm{K}_{\mathrm{sp}}\right)$ of $\mathrm{Zn}(\mathrm{OH})_{2}$ is exceeded a precipitation and dehydration reaction occurs and $\mathrm{ZnO}$ is deposited. For - $\mathrm{COOH}$ terminated SAMs, the CBD reaction proceeds via a mixed ion-by-ion deposition and cluster-by-cluster growth [10]. The deposition is strongly temperature dependent; at $318 \mathrm{~K}$ deposition is observed but at room temperature there is no $\mathrm{ZnO}$ [10]. The ion-by-ion deposition leads to an underlayer of uniform nanocrystals strongly which strongly adhere to the substrate. In contrast, there are larger $\mathrm{ZnO}$ nanocrystals which are deposited by cluster-by-cluster deposition. These larger crystals exhibit many different morphologies and do not strongly adhere to the substrate. Although the $\mathrm{ZnO}$ CBD process appears to be simple, we observe that the nanocrystals formed by cluster-by-cluster deposition follow a complicated reaction pathway. At low $\mathrm{Zn}^{2+}$ and $\mathrm{OH}^{-}$concentrations nanorods form. These nanorods grow slowly suggesting that there is a low supersaturation concentration close to the surface [15]. At higher reagent concentrations, ZnO deposition occurs via multiple nucleation and growth steps. In this regime more complex ZnO nanocrystals, nanoflowers and nanorockets, are observed.

\section{Experimental}

\subsection{Materials}

Zinc acetate dihydrate $(\geq 98.0 \%)$, mercaptohexadecanoic acid $(99 \%)$ and ethylenediamine $(\geq 99.5 \%)$ were acquired from Sigma Aldrich (St. Louis, MO). Gold and chromium were purchased from Alfa Aesar Inc. (Ward Hill, MA) and were of 99.995\% purity. All reagants were used without further purification. Silicon 
wafers ( $<111>$ orientation) were obtained from Addison Engineering Inc. (San Jose, CA) and prior to use etched using piranha etch $\left(\mathrm{H}_{2} \mathrm{SO}_{4}: \mathrm{H}_{2} \mathrm{O}_{2}=3: 1\right)$.

\subsection{Self-Assembled Monolayer Preparation}

The $-\mathrm{COOH}$ terminated SAMs were prepared and characterized using to previously published procedures [24-26]. In brief, a Cr adhesion layer ( $50 \AA$ ) followed by a Au layer ( 1000 $\AA$ ) were sequentially thermally deposited onto freshly etched Si wafers. The prepared Au substrates were immersed into a 1 $\mathrm{mM}$ ethanolic solution of the mercaptohexadecanoic acid for $24 \mathrm{~h}$ at ambient temperature (294 $\pm 2 \mathrm{~K})$ to form well-organized - $\mathrm{COOH}$ terminated SAMs on Au substrates. For each batch, one sample was taken and characterized using single-wavelength ellipsometry (Gaertner Scientific Corp., Skokie, IL) and timeof-flight secondary ion mass spectrometry (TOF SIMS) to ensure that the SAMs were free of significant chemical contamination.

\subsection{ZnO Chemical Bath Deposition}

The ZnO plating solution consists of $0.0036 \mathrm{M}$ to $0.036 \mathrm{M}$ Zn acetate and $0.0036 \mathrm{M}$ to $0.084 \mathrm{M}$ ethylenediamine (complexing agent). The plating solution was prepared as follows: first, Zn acetate was dissolved in deionized water, and then ethylenediamine was added dropwise into the solution. During en addition the white precipitate initially formed re-dissolved. The deposition was performed at $318 \mathrm{~K}$ (45 ${ }^{\circ} \mathrm{C}$ ) for times from $10 \mathrm{~min}$ to $2 \mathrm{~h}$. The $\mathrm{pH}$ of the plating solution varied from 7.6 to 10.8. For some experiments the bath $\mathrm{pH}$ was adjusted using sodium hydroxide. After chemical bath deposition, samples were rinsed thoroughly with deionized water and then ethanol. They were dried using nitrogen gas and immediately transferred to the scanning electron microscope or X-ray diffractometer for analysis.

\subsection{Scanning Electron Microscopy}

Scanning electron microscopy (SEM) measurements were obtained using a dual-beam FIB instrument (Nova 200 Nanolab, FEI Company) with an electron beam energy of $5 \mathrm{keV}$. The size and number density of the $\mathrm{ZnO}$ nanostructures was obtained from high resolution SEM images using ImageJ [27, 28]. Between 50 and 100 nanostructures were measured to obtain their dimensions (length and width). At least 10 images (area: $25 \times 25 \mu^{2}$ ) were measured to obtain the number density (number of nanostructures per 
$\mu \mathrm{m}^{2}$ ). The ratio of sphelurites to nanoflowers, or precursor crystallites to nanorockets, was calculated from these images for each deposition time. The data reported is the average of these measurements and reported error is the standard deviation.

\subsection{X-ray Diffraction}

Grazing incident X-ray diffraction (XRD) patterns were acquired using a Rigaku Ultima III diffractometer ( $\mathrm{Cu} \mathrm{K} \alpha$ radiation) equipped with a glancing angle detector. Measurements were taken at an angle of $0.2^{\circ}$, for $2 \theta$ values over $25-70^{\circ}$ in steps of $0.01^{\circ}$ with a scanning rate of $1 \% \mathrm{~min}$.

\subsection{X-ray Photoelectron Spectroscopy}

Ex situ x-ray photoelectron spectroscopy (XPS) was performed using a Versa Probe II (Physical Electronics, Inc., Chanhassen, $\mathrm{MN})$, using an $\mathrm{Al} \mathrm{K} \alpha$ source $(\mathrm{E}=1486.7 \mathrm{eV})$. The vacuum for measurement was typically lower than $6 \times 10^{-8}$ Pa. All XPS spectra were measured with a step energy of $0.125 \mathrm{eV}$ and pass energy of $29.35 \mathrm{eV}$. The data were collected at $45^{\circ}$ to the normal of the sample surface. The binding energies were calibrated using the $\mathrm{Au} 4 \mathrm{f}_{7 / 2}$ binding energy $(84.0 \mathrm{eV})$. The spectra were analyzed using CasaXPS 2.3.16 (RBD Instruments, Inc., Bend, OR) and AAnalyzer 1.07.

\section{Results and Discussion}

\subsection{Deposit Chemical Composition and Crystal Structure}

The composition and crystal structure of the deposits was monitored using XPS (spectra not shown) and XRD (Figure 1). In XPS for all the deposited films (including different deposition times), the binding energy of $\mathrm{Zn} 2 \mathrm{p}_{3 / 2}$ is $1022.3 \pm 0.2 \mathrm{eV}$ and the spin-orbit splitting is $23.1 \mathrm{eV}$ is consistent with $\mathrm{Zn}$ in the $2+$ oxidation state and the deposition of $\mathrm{ZnO}[29,30]$. However, the measured $\mathrm{Zn} 2 \mathrm{p}_{3 / 2}$ binding energy is also in the range with $\mathrm{Zn}(\mathrm{OH})_{2}(\sim 1021.7-1022.7 \mathrm{eV})$ [29, 30], and so we determined the modified Auger parameter ( 2009.8 $\pm 0.2 \mathrm{eV}$ ) which is consistent with $\mathrm{ZnO}(2009.5-2011.0 \mathrm{eV})$ [30]. The O 1s spectra also indicate that $\mathrm{ZnO}$ was deposited. The $\mathrm{O} / \mathrm{Zn}$ ratio determined from the XPS spectra is $0.78 \pm 0.08$, which is much smaller than expected for the stoichiometry of $\mathrm{ZnO}$ and suggests that the films are oxygen deficient. However, the Zn LMM Auger peak, which is more sensitive to the oxidation state of $\mathrm{Zn}$, 
indicates that the there is only one species of Zn present in the +2 oxidation state. Thus the XPS spectra confirm that $\mathrm{ZnO}$ is deposited under all conditions and the deposited $\mathrm{ZnO}$ is likely stoichiometric not oxygen deficient. The XRD data indicate that the deposited ZnO crystallites are zincite (hexagonal phase, space group P63mc, JCPDS no. 00-036-1451), and do not appear to have preferential growth directions (Figure 1).

\subsection{Deposit Morphologies}

After $1 \mathrm{~h} \mathrm{CBD}$ at $318 \mathrm{~K}$ a wide variety of $\mathrm{ZnO}$ morphologies formed by cluster-by-cluster growth are observed on $-\mathrm{COOH}$ terminated SAMs at different zinc acetate $\left(\mathrm{Zn}^{2+}\right)$ and ethylenediamine ratios and precursor concentrations. For example, at $[\mathrm{en}]:\left[\mathrm{Zn}^{2+}\right]=1.25$, the $\mathrm{ZnO}$ deposit morphology varies from nanorods to nanoflowers/sphelurites as the $\mathrm{Zn}^{2+}$ concentration changes from $0.018 \mathrm{M}$ to $0.0036 \mathrm{M}$ (Figure 2). As the [en]:[ $\left.\mathrm{Zn}^{2+}\right]$ is varied from $1: 1$ to $1: 2.33$ at $\left[\mathrm{Zn}^{2+}\right]=0.018 \mathrm{M}$, the $\mathrm{ZnO}$ morphology changes from nanorods to nanorockets to nanoflowers (Figure 3).

Figure 4 displays the dependence of the $\mathrm{ZnO}$ deposit morphology on $\left[\mathrm{Zn}^{2+}\right]$, [en]:[ $\left.\mathrm{Zn}^{2+}\right]$ and bath $\mathrm{pH}$. We note that the boundaries between the different morphologies remain constant for all deposition times studied (see below, section 3.3). At high [en]:[ $\left.\mathrm{Zn}^{2+}\right]$ ([en]:[ $\left.\mathrm{Zn}^{2+}\right] \gtrsim 2.5$ ) no deposition is observed which is most likely due to the formation of soluble $\mathrm{Zn}(\mathrm{OH})_{4}{ }^{2-}$ ions (Figure 4a). If the concentration of zinc acetate is too high $\left(\left[\mathrm{Zn}^{2+}\right] \geq 0.036 \mathrm{M}\right)$ and $[\mathrm{en}]:\left[\mathrm{Zn}^{2+}\right]$ is low $\left([\mathrm{en}]:\left[\mathrm{Zn}^{2+}\right] \leq 1\right)$, the bath solution is cloudy and viscous indicating that $\mathrm{Zn}(\mathrm{OH})_{2}$ is precipitated. Since the ethylenediamine concentration affects the $\mathrm{pH}$ of the solution, alternatively we can examine the dependence of the $\mathrm{ZnO}$ morphology on the deposition bath $\mathrm{pH}$ (Figure 4b). In Figure $4 \mathrm{~b}$ it can be seen that the $\mathrm{ZnO}$ morphology is closely related to the deposition bath $\mathrm{pH}$ as well as [en]:[ $\mathrm{Zn}^{2+}$ (Figure 4a). Indeed the bath $\mathrm{pH}$ is almost linearly dependent on [en]:[ $\left.\mathrm{Zn}^{2+}\right]$ (data not shown). In agreement with previously measured isoelectric points of ZnO (pI 8.0 - 10.3) [31-33], which are the pHs at which ZnO has minimum solubility, ZnO deposition occurs from $\mathrm{pH} \sim 7.7$ to 10.5 . Nanorods and nanorockets are deposited in a narrow range of $\mathrm{pH}$ from $\sim 7.7$ to $\sim 8.5$ and at $\left[\mathrm{Zn}^{2+}\right] \geq 0.01 \mathrm{M}$. In contrast nanoflower structures are deposited over a wide pH range $\sim 8.0$ to $\sim 10.5$ and over an order of magnitude in $\mathrm{Zn}^{2+}$ concentrations from $0.0036 \mathrm{M}$ to $0.036 \mathrm{M}$. It is also 
interesting to note that nanoflower and sphelurite growth occurs over the entire $\mathrm{pH}$ range but only at low $\mathrm{Zn}^{2+}$ concentrations $\left(\left[\mathrm{Zn}^{2+}\right] \leq 0.01 \mathrm{M}\right)$. We also note that within a class of nanomaterial, the bath $\mathrm{pH}$ (and hence the ratio of $\left.[\mathrm{en}]:\left[\mathrm{Zn}^{2+}\right]\right)$ is critical in determining the detailed morphology of the deposited $\mathrm{ZnO}$ (Figure 3). For example, at $\left[\mathrm{Zn}^{2+}\right]=0.018 \mathrm{M}$ at pH $7.8\left([\mathrm{en}]:\left[\mathrm{Zn}^{2+}\right]=1\right)$, the deposited $\mathrm{ZnO}$ nanorods have a hexagonal structure, while at pH $8.2\left([\mathrm{en}]:\left[\mathrm{Zn}^{2+}\right]=1.25\right)$ the nanorods are more rounded and have a less well-defined structure (“fluffy" nanorods).

These results also appear to show that the $\mathrm{Zn}^{2+}$ concentration is important for controlling the $\mathrm{ZnO}$ morphology. For example at $\mathrm{pH} 7.8$, nanorockets are observed at $\left[\mathrm{Zn}^{2+}\right]=0.0009 \mathrm{M}$ while nanorods form at $\left[\mathrm{Zn}^{2+}\right]=0.0018 \mathrm{M}$ (Figure $4 \mathrm{~b}$ ). However, in these depositions the [en] to $\left[\mathrm{Zn}^{2+}\right]$ ratio is also changing which affects the concentration of "free" $\mathrm{Zn}^{2+}$ (uncomplexed $\mathrm{Zn}^{2+}$ which is available for reaction). To test the hypothesis that the "free" $\mathrm{Zn}^{2+}$ concentration is critical in determining the $\mathrm{ZnO}$ morphology, the solution $\mathrm{pH}$ was adjusted using sodium hydroxide. At $\left[\mathrm{Zn}^{2+}\right]=0.018 \mathrm{M}$ and $[\mathrm{en}]:\left[\mathrm{Zn}^{2+}\right]=1: 1$, if the $\mathrm{pH}$ is adjusted to 9.5 (from pH 7.8) using sodium hydroxide hexagonal nanorods are observed to deposit (data not shown). In contrast, if the bath $\mathrm{pH}$ is adjusted to 9.5 using ethylenediamine ([en]: $\left[\mathrm{Zn}^{2+}\right] \sim 1.75$ ), which in effect reduces the "free" $\mathrm{Zn}^{2+}$ concentration, nanoflowers form (Figure 4b). These observations indicate that the "free" $\mathrm{Zn}^{2+}$ concentration is important in determining the deposited $\mathrm{ZnO}$ morphology.

\subsection{Growth Mechanisms of ZnO Nanostructures}

\subsubsection{Nanorods}

At low $\mathrm{pH}\left(\mathrm{pH} \lesssim 8.2\right.$; low $[\mathrm{en}] /\left[\mathrm{Zn}^{2+}\right]$ ratios) and high $\mathrm{Zn}^{2+}$ concentrations, nanorods form at all deposition times studied (10 min to $2 \mathrm{~h}$ ) (Figure 5). The nanorod dimensions (height, width) remain constant (within experimental error) with deposition time (Table 1). The hexagonal and "fluffy" nanorod morphologies have similar lengths and widths (Table 2). The number density of the nanorods (number per unit area) increases approximately linearly with deposition time (Figure 6). We note that the number density of the hexagonal rods is approximately $20 \%$ of the "fluffy" rods. This is most likely due to the slower reaction rate between $\mathrm{Zn}^{2+}$ and $\mathrm{OH}^{-}$because there is a lower $\mathrm{OH}^{-}$concentration ([en]). Taken 
together the slow growth and linear increase in number of nanorods with deposition time suggests that they are formed low supersaturation conditions [15].

For all nanorods synthesized, a clear interface, or waist, is observed in the middle of the crystal (Figures 2, 3, and 5). The two halves of the nanorod can have different dimensions indicating that the nanorods are composed of crystals with two different growth directions. It is also interesting to note that for "fluffy" nanorods, the cross-section of the nanostructure is hexagonal suggesting that the growth is dominated by maximizing the areas of $\{2 \overline{1} \overline{1} 0\}$ and $\{0 \overline{1} \overline{1} 0\}$ facets to minimize surface energy in a similar manner to hexagonal nanorods grown by gas phase processes [1].

\subsubsection{Nanorockets and Nanoflowers}

At higher [en] to $[\mathrm{Zn}]$ ratios, we observe first nanorockets ([en]:[Zn] 1:1.5) and then nanoflowers (Figure 3). Our data indicates that these $\mathrm{ZnO}$ crystallites do not form from nanorods as proposed by Sounart et al. [9], Gao et al. [17], and Cho et al. [12]. At early deposition times ( $<20$ mins) the deposits are composed mostly of nanocrystallites (Figures 7 and 8). At later deposition times the number of these nanoparticles significantly decreases, while the number of nanoflowers or nanorockets significantly increases (Figures 7 and 8). These observations suggest that the nanocrystallites act as the nuclei for the subsequent growth of the more complex nanostructures. We note that the precursor crystallite morphology differs for nanorockets or nanoflowers. For nanoflowers the precursor crystallites are composed of spherlurites (Figure 7), while for nanorockets the nanocrystallites have a less well-defined structure (Figure 8).

The data also indicate that the fraction of the nanocrystallites decreases exponentially with deposition time (Figure 9). After 40 mins deposition, for nanoflowers the sphelurites comprise less than $0.15 \%$ of the $\mathrm{ZnO}$ deposit (sphelurite:nanoflower $\approx 1.5 \times 10^{-3}$ ) (Figure 9a). In contrast, the nanorockets, the precursor crystallites comprise a larger proportion of the $\mathrm{ZnO}$ deposit. After $\sim 40$ mins $\mathrm{ZnO}$ deposition, the precursor crystallites are $\sim 30 \%$ (crystallite:nanorocket $\approx 0.4$ ) of the observed deposit

(Figure 9b). Concomitantly, the number density (number per $\mu \mathrm{m}^{2}$ ) of the $\mathrm{ZnO}$ nanoflowers and nanorockets increases (Figure 10). 
Taken together the data indicates that the nanorockets and nanoflowers grow via a modified La Mer mechanism. In this mechanism there are several nucleation events. After the first nucleation $(<<10$ min deposition time), the precursor crystallites (e.g. sphelurites) begin to grow by diffusion of the reactants to the growing surface. However, at a critical concentration, nucleation no longer takes place and existing nanostructures grow until a critical solubility is reached. The low concentration of $\mathrm{Zn}^{2+}$ (nanoflowers) or $\mathrm{OH}^{-}$(nanorockets) requires that for the deposited particles to increase in size, dissolution and re-precipitation must occur. Since the reaction is kinetically controlled and not in the thermodynamic limit, the nucleation rate of the nanoflowers or nanorockets is not constant. Thus, the fraction of precursor crystallites decreases exponentially with time [34, 35]. A second consequence is that the growth of the subsequent nanostructures is slow. For example, the number density of nanoflowers increases only by two-fold over the deposition times studied. At higher $\left[\mathrm{Zn}^{2+}\right]$ or $\left[\mathrm{OH}^{-}\right]$(higher $\mathrm{pH}$ or $[\mathrm{en}]$ ), no precursor crystallites are observed prior to the formation of nanoflowers because the reaction rate is faster.

Nanoflower (star-like) ZnO morphologies have been observed using a number of different deposition methods [16]. It has been proposed that nanoflowers form via $\mathrm{ZnO}$ particles twinned along the $(112 \overline{2})$ planes [16]. Zinc oxide nanosheets form between the spines which can act as the nuclei for further spines to grow leading to the formation of nanoflowers. In agreement with this proposed reaction pathway, we observe that the number of nanoflower petals increases with deposition time (Figure 7). After 15 mins, the nanoflowers typically have one to seven petals, and after 45 mins deposition we observe that each nanoflower has at least six petals.

Nanorockets also appear to form in a similar manner to the nanoflowers. We observe for a nanorocket that there is one dominant spine which is ellipsoidal in shape and comprises the body of the nanorocket (Figure 8). As the deposition time increases the number of spines on the ellipsoidal "body" of the rocket increases. After 15 mins, the nanorockets have zero to three spines whereas after 45 mins the number of spines generally increases to between two and five spines. It is likely that the spine formation is very slow due to the low $\mathrm{OH}^{-}$concentration relative to the $\mathrm{Zn}^{2+}$ concentration, and so a limited number of spines can form in a given reaction time. 


\section{Conclusions}

We have performed a systematic study of the solution-based synthesis of ZnO nanocrystallites. Our studies show that at given deposition temperature there are two critical factors a) the concentration of $\mathrm{Zn}^{2+}$ ions and b) the deposition bath $\mathrm{pH}$.

More generally our study shows the importance of twinned crystal structures in the synthesis of a variety of nanocrystallite morphologies. $\mathrm{ZnO}$ nanorods form at high $\mathrm{Zn}^{2+}$ concentration but low $\mathrm{OH}^{-}$concentration. All nanorods studied exhibit a clear interface in the middle of the crystal indicating that they are likely composed of twinned structures. In contrast to previously postulated mechanisms, nanorods are not the nuclei for hieracrchical nanostructures, such as nanoflowers and nanorockets. Rather, they appear to form via a modified LaMer mechanism. Sphelurites or nanocrystallites act as the precursors to the nanoflowers and nanorockets. The nanoflowers and nanorockets then form in a second nucleation step in which twinned crystals act as the nuclei for further spines to grow. In agreement with this proposed mechanism we observe that the number of spines or petals increases with deposition time.

\section{Acknowledgements}

We gratefully acknowledge support from the National Science Foundation (CHE 1213546).

\section{References}

[1] Z.L. Wang, Zinc Oxide Nanostructures: Growth, Properties and Applications, J. Phys.: Condens. Matter 16 (2004) R829-R858.

[2] X. Wang, J. Song, Z.L. Wang, Nanowire and Nanobelt Arrays of Zinc Oxide from Synthesis to Properties and to Novel Devices, J. Mater. Chem. 17/8 (2007) 711-720.

[3] D. Panda, T.-Y. Tseng, One-Dimensional ZnO Nanostructures: Fabrication, Optoelectronic Properties, and Device Applications, J. Mater. Sci. 48 (2013) 6849-6877.

[4] S. Roy, N. Banerjee, C.K. Sarkar, P. Bhattacharyya, Development of an Ethanol Sensor Based on CBD Grown ZnO Nanorods, Solid-State Electron. 87 (2013) 43-50. 
[5] G.-C. Yi, C. Wang, W.I. Park, ZnO Nanorods: Synthesis, Characterization and Applications, Semicond. Sci. Technol. 20 (2005) S22-S34.

[6] J.B. Chu, S.M. Huang, D.W. Zhang, Z.Q. Bian, X.D. Li, Z. Sun, X.J. Yin, Nanostructured ZnO Thin Films by Chemical Bath Deposition in Basic Aqueous Ammonia Solutions for Photovoltaic Applications, Appl. Phys. A 95 (2009) 849-855.

[7] A. Drici, G. Djeteli, G. Tchangbedji, H. Derouiche, K. Jondo, K. Napo, J.C. Bernède, S. OuroDjobo, M. Gbagba, Structured ZnO Thin Films Grown by Chemical Bath Deposition for Photovoltaic Applications, Phys. Status Solidi A 201 (2004) 1528-1536.

[8] G. Hodes, Chemical Solution Deposition of Semiconductor Films, Marcel Dekker, Inc., New York, Basel, 2002.

[9] T.L. Sounart, J. Liu, J.A. Voigt, J.W.P. Hsu, E.D. Spoerke, Z.R. Tian, Y. Jiang, Sequential Nucleation and Growth of Complex Nanostructrured Films, Adv. Funct. Mater. 16 (2006) 335-344. [10] Z. Shi, A.V. Walker, Chemical Bath Deposition of ZnO on Functionalized Self-Assembled Monolayers: Selective Deposition and Control of Deposit Morphology, Langmuir 31 (2015) 1421-1428.

[11] P. Lu, A.V. Walker, Making Nanoflowerbeds: Reaction Pathways Involved in the Selective Chemical Bath Deposition of ZnS on Functionalized Alkanethiolate Self-Assembled Monolayers, ACS Nano 3 (2009) 370-378.

[12] S. Cho, H. Jeong, D.-H. Park, S.-H. Jung, H.-J. Kim, K.-H. Lee, The Effects of Vitamin C on ZnO Crystal Formation, CrystEngComm 12 (2010) 968-976.

[13] T. Trindade, J.D.P. de Jesus, P. O'Brien, Preparation of Zinc Oxide and Zinc Sulfide Powders by Controlled Precipitation from Aqueous Solution, J. Mater. Chem. 4/10 (1994) 1611-1617.

[14] B. Cao, W. Cai, From ZnO Nanorods to Nanoplates: Chemical Bath Deposition Growth and Surface-Related Emissions, J. Phys. Chem. C 112 (2008) 680-685.

[15] K. Govender, D.S. Boyle, P.B. Kenway, P. O'Brien, Understanding the Factors that Govern the Deposition and Morphology of Thin Films of ZnO from Aqueous Solution, J. Mater. Chem. 14 (2004) 2575-2591. 
[16] R.A. McBride, J.M. Kelly, D.E. McCormack, Growth of Well-Defined ZnO Microparticles by Hydroxide Ion Hydrolysis of Zinc Salts, J. Mater. Chem. 13 (2003) 1196-1201.

[17] X. Gao, X. Li, W. Yu, Flowerlike ZnO Nanostructures via Hexamethylenetetramine-Assisted Thermolysis of Zinc-Ethylenediamine Complex, J. Phys. Chem. B 109 (2005) 1155-1161.

[18] A.P.A. Oliveira, J.-F. Hochpied, F. Grillon, M.-H. Berger, Controlled Precipitation of Zinc Oxide Particles at Room Temperature, Chem. Mater. 15 (2003) 3202-3207.

[19] O. Singh, N. Kohli, R.C. Singh, Precursor Controlled Morphology of Zinc Oxide and its Sensing Behavior, Sens. Actuators B 178 (2013) 149-154.

[20] A.M. Ali, E.A.C. Emanuelsson, D.A. Patterson, Photocatalysis with Nanostructured Zinc Oxide Thin Films: The Relationship Between Morphology and Photocatalytic Activity Under Oxygen Rich Conditions and Evidence for a Mars Van Krevelen Mechanism, Appl. Catal. B 97 (2010) 168-181.

[21] D. Doutt, H.L. Mosbacker, G. Cantwell, J. Zhang, J.J. Song, L.J. Brillson, Impact of NearSurface Defects and Morphology on ZnO Luminescence, Appl. Phys. Lett. 94 (2009) art. no. 042111. [22] H. Khallaf, G. Chai, O. Lupan, H. Heinrich, S. Park, A. Schulte, L. Chow, Investigation of Chemical Bath Deposition of ZnO Thin Films Using Six Different Complexing Agents, J. Phys. D: Appl. Phys. 42 (2009) art. no. 135304.

[23] O.Y. Kurtova, V.I. Kravstov, E.G. Tsventarnyi, Ethylenediamine and Hydroxyethylenediamine Complexes of Zinc(II): A Potentiometric Study of Composition and Stability, Russ. J. Electrochem. 40 (2004) 893-897.

[24] R.G. Nuzzo, L.H. Dubois, D.L. Allara, Fundamental Studies of Microscopic Wetting on Organic Surfaces. 1. Formation and Structural Characterization of a Self-Consistent Series of Polyfunctional Organic Monolayers, J. Am. Chem. Soc. 112 (1990) 558-569.

[25] C.D. Bain, H.A. Biebuyck, G.M. Whitesides, Comparison of Self-Assembled Monolayers on Gold: Coadsorption of Thiols and Disulfides, Langmuir 5 (1989) 723-727. 
[26] G.L. Fisher, A.E. Hooper, R.L. Opila, D.L. Allara, N. Winograd, The Interaction of Vapor-

Deposited $\mathrm{Al}$ Atoms with $\mathrm{CO}_{2} \mathrm{H}$ Groups at the Surface of a Self-Assembled Alkanethiolate Monolayer on Gold, J. Phys. Chem. B 104 (2000) 3267-3273.

[27] C.A. Schneider, W.S. Rasband, K.W. Eliceiri, NIH Image to ImageJ: 25 years of image analysis, Nat. Meth. 9/7 (2012) 671-675.

[28] W.S. Rasband Image J. http://imagej.nih.gov/ij/

[29] Y.-S. Min, C.J. An, S.K. Kim, J. Song, C.S. Hwang, Growth and Characterization of Conducting ZnO Thin Films by Atomic Layer Deposition, Bull. Korean Chem. Soc. 31 (2010) 2503-2508.

[30] NIST X-ray Photoelectron Spectroscopy Database, Version 4.1 (National Institute of Standards and Technology, Gaithersburg, 2012), 2012

[31] G.A. Parks, The Isoelectric Points of Solid Oxides, Solid Hydroxides, and Aqueous Hydroxo Complex Systems, Chem. Rev. 65/2 (1965) 177-198.

[32] N.F. Bogdanova, L.E. Ermakova, G.L. Strelkov, E.V. Golikova, Colloido-chemical characteristics of zinc oxide in electrolyte solutions, Colloid Journal 75/1 (2013) 1-6.

[33] R. Marsalek, Particle Size and Zeta Potential of ZnO, APCBEE Procedia 9 (2014) 13-17.

[34] R.P. Sear, Quantitative Studies of Crystal Nucleation at Constant Supersaturation: Experimental Data and Models, CrystEngComm 16 (2014) 6506-6522.

[35] G.M. Pound, V.K. La Mer, Kinetics of Crystalline Nucleus Formation in Supercooled Liquid Tin, J. Am. Chem. Soc. 74 (1952) 2323-2332. 
Table 1. Dimensions of nanorods after $\mathrm{ZnO}$ chemical bath deposition $\left(\left[\mathrm{Zn}^{2+}\right]=0.018 \mathrm{M}\right.$, [en]: $\left[\mathrm{Zn}^{2+}\right]=$ 1.25:1) on -COOH terminated SAMs at $318 \mathrm{~K}$ for different deposition times.

\begin{tabular}{|l|l|l|}
\hline \multirow{2}{*}{$\begin{array}{l}\text { Deposition Time } \\
(\mathrm{min})\end{array}$} & \multicolumn{2}{|l|}{ Dimensions (nm) } \\
\cline { 2 - 3 } & Width & Length \\
\hline 15 & $386 \pm 68$ & $642 \pm 160$ \\
\hline 30 & $262 \pm 35$ & $433 \pm 81$ \\
\hline 45 & $403 \pm 64$ & $758 \pm 165$ \\
\hline 60 & $305 \pm 42$ & $642 \pm 134$ \\
\hline 90 & $309 \pm 63$ & $575 \pm 145$ \\
\hline 120 & $414 \pm 65$ & $875 \pm 169$ \\
\hline
\end{tabular}

Table 2. Average dimensions of hexagonal and "fluffy" nanorods after 1 h deposition at $318 \mathrm{~K}$.

\begin{tabular}{|l|l|l|l|}
\hline \multicolumn{2}{|l|}{ Hexagonal Nanorod } & \multicolumn{2}{l|}{ "Fluffy" Nanorod } \\
\hline $\begin{array}{l}\text { Width } \\
\text { (nm) }\end{array}$ & $\begin{array}{l}\text { Length } \\
\text { (nm) }\end{array}$ & Width (nm) & $\begin{array}{l}\text { Length } \\
\text { (nm) }\end{array}$ \\
\hline $332 \pm 134$ & $845 \pm 193$ & $305 \pm 42$ & $642 \pm 134$ \\
\hline
\end{tabular}




\section{Figure Captions}

Figure 1. XRD pattern of $\mathrm{ZnO}$ crystallites deposited on - $\mathrm{COOH}$ terminated SAM surface. Reaction conditions: deposition time 1h, deposition bath temperature $318 \mathrm{~K}$.

Figure 2. SEM images after $\mathrm{ZnO}$ chemical bath deposition for $1 \mathrm{~h}$ on $-\mathrm{COOH}$ terminated SAMs at $318 \mathrm{~K}$ and $[\mathrm{en}]:\left[\mathrm{Zn}^{2+}\right]=1.25$. The concentration of $\mathrm{Zn}^{2+}$ is varied from $0.018 \mathrm{M}$ to $0.0036 \mathrm{M}$.

Figure 3. SEM images after $\mathrm{ZnO}$ chemical bath deposition for $1 \mathrm{~h}$ on $-\mathrm{COOH}$ terminated SAMs at $318 \mathrm{~K}$ and $\left[\mathrm{Zn}^{2+}\right]=0.018 \mathrm{M}$. The ratio of $[\mathrm{en}]:\left[\mathrm{Zn}^{2+}\right]$ is varied from 1:1 to 2.33:1.

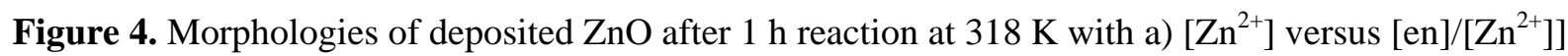
and b) $[\mathrm{Zn}]$ versus $\mathrm{pH}$. The dashed lines are drawn as a guide to the eye.

Figure 5. SEM images after $\mathrm{ZnO}$ chemical bath deposition $\left(\left[\mathrm{Zn}^{2+}\right]=0.018 \mathrm{M}\right.$, [en]: $\left.\left[\mathrm{Zn}^{2+}\right]=1.25: 1\right)$ on -COOH terminated SAMs at $318 \mathrm{~K}$ for different deposition times.

Figure 6. Number density (number per $\mu \mathrm{m}^{2}$ ) of "fluffy" nanorods with deposition time. Reaction conditions: deposition temperature $318 \mathrm{~K},\left[\mathrm{Zn}^{2+}\right]=0.018 \mathrm{M}$, [en]:[ $\left.\mathrm{Zn}^{2+}\right]=1.25: 1$. The dotted line is a linear fit to the data with a slope of $0.03 \mu \mathrm{m}^{-2} \mathrm{~min}^{-1}$.

Figure 7. SEM images after $\mathrm{ZnO}$ chemical bath deposition $\left([\mathrm{Zn}]=0.0036 \mathrm{M}\right.$, [en]:[$\left[\mathrm{Zn}^{2+}\right]=2: 1$ on -COOH terminated SAMs at $318 \mathrm{~K}$ for different deposition times.

Figure 8. SEM images after ZnO chemical bath deposition ([Zn] $=0.0009 \mathrm{M}$, [en]:[Zn] = 1.25:1) on - $\mathrm{COOH}$ terminated SAMs at $318 \mathrm{~K}$ for different deposition times.

Figure 9. The ratio of the number of a) sphelurites to nanoflowers and b) nanocrystallites to nanorockets with deposition time. Deposition conditions are given in Figure 7 (a) and Figure 8 (b). The data was fit to an exponential with the form $\mathrm{y}=\mathrm{c}+\mathrm{bexp}(-\mathrm{at})$ where $\mathrm{a}, \mathrm{b}$ and $\mathrm{c}$ are constants and $\mathrm{t}$ is the deposition time. The goodness of fit $r^{2}$ is in (a) 0.999 and (b) 0.906 .

Figure 10. Number density (number per $\mu \mathrm{m}^{-2}$ ) of a) nanoflowers and b) nanorockets with deposition time. Deposition conditions are given in Figures 7 and 8 for nanoflowers and nanorockets respectively. 


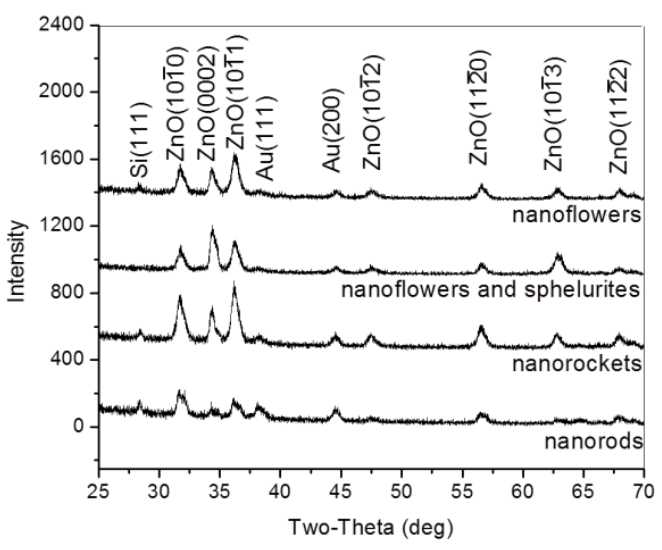

Figure 1 


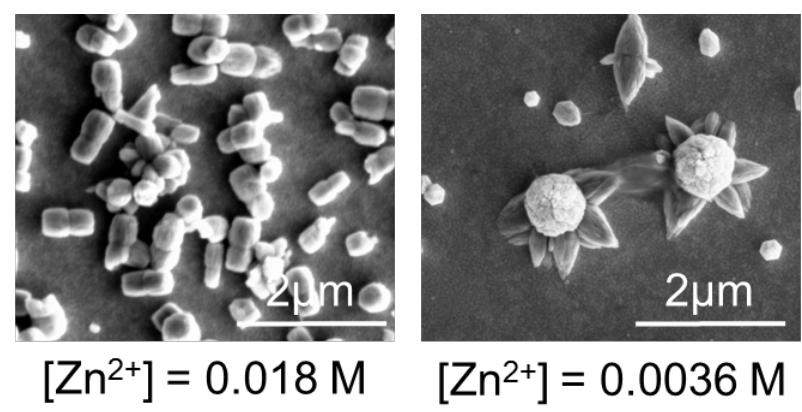

Figure 2 

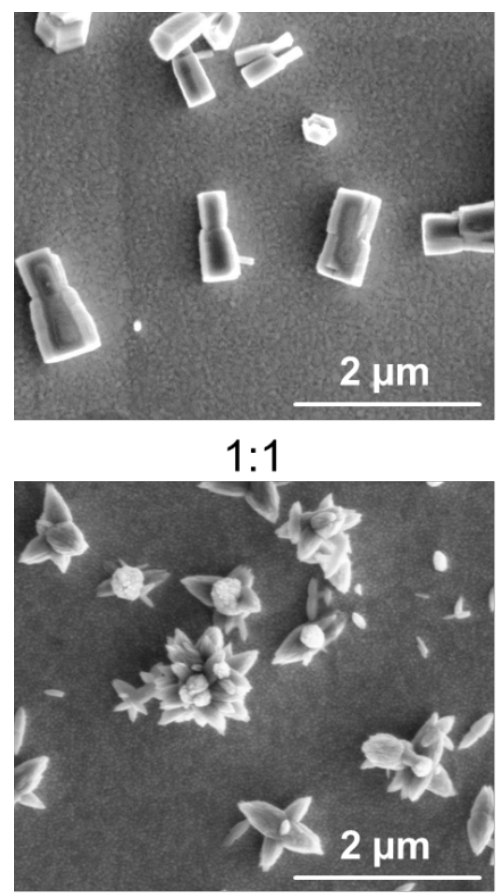

1.75:1

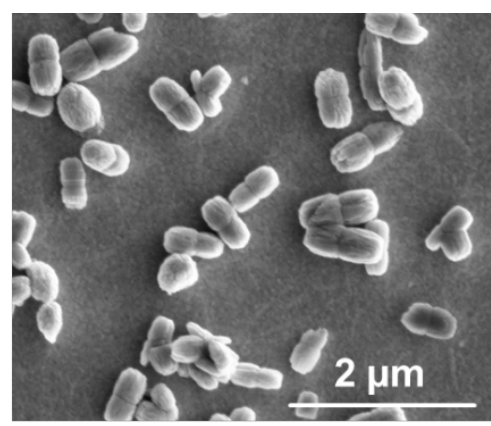

1.25:1

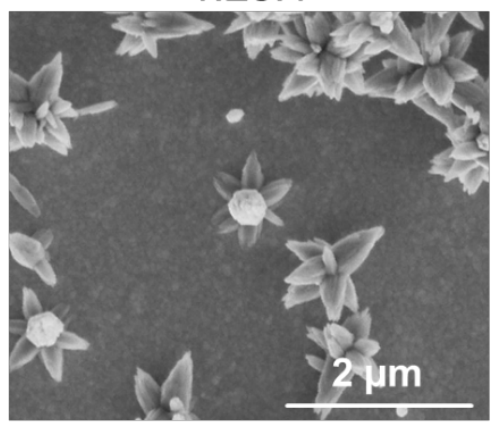

2:1

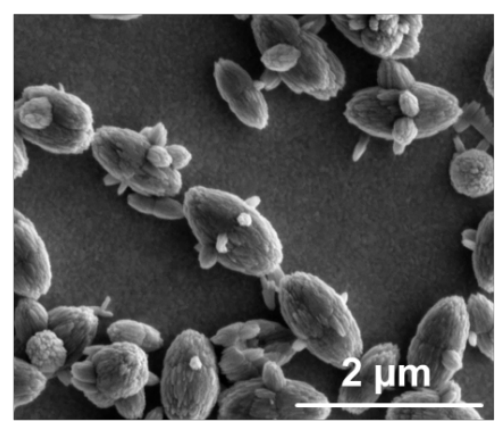

1.5:1

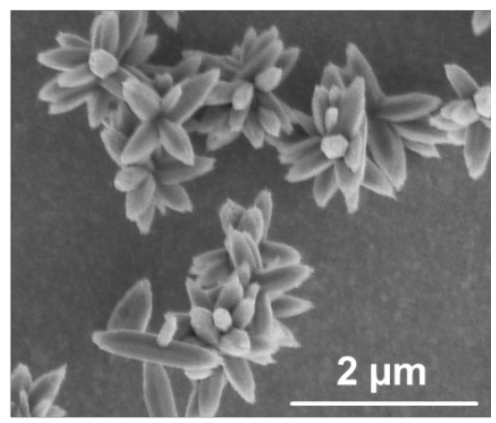

2.33:1

Figure 3 

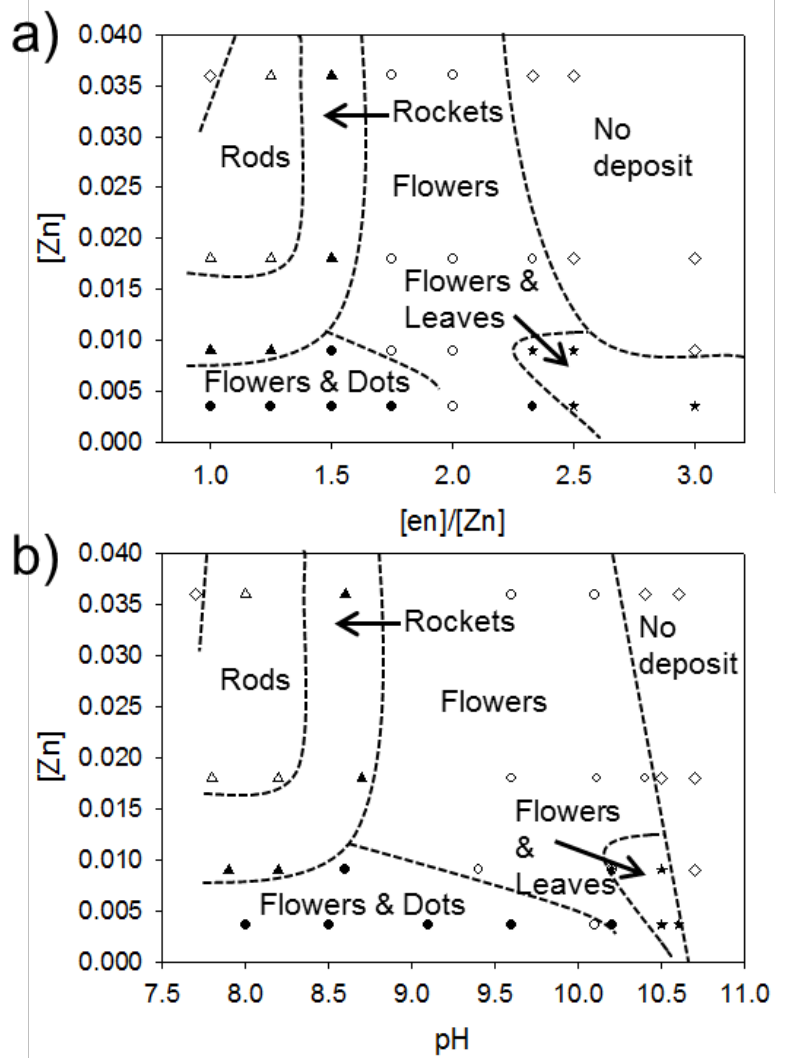

Figure 4 

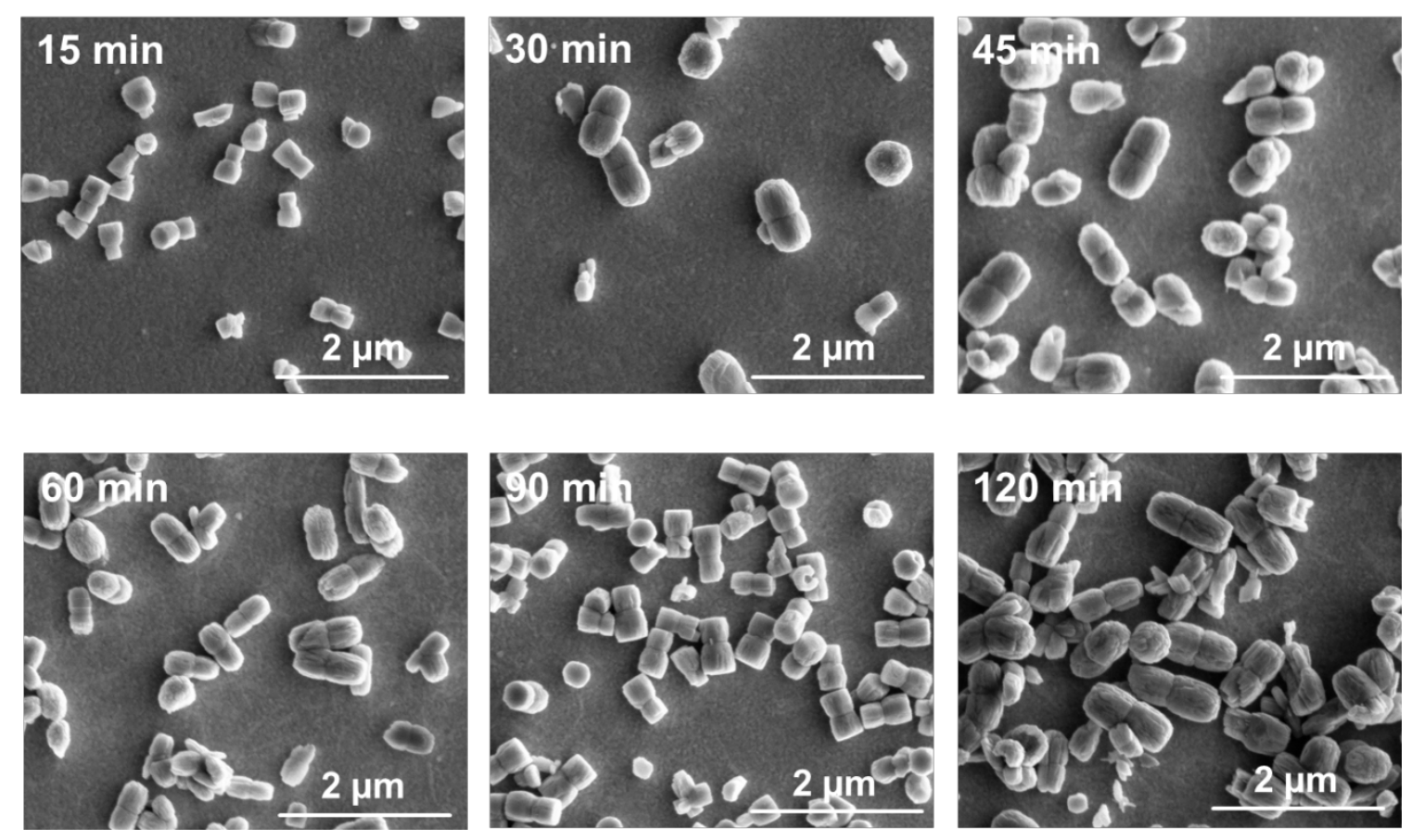

Figure 5 


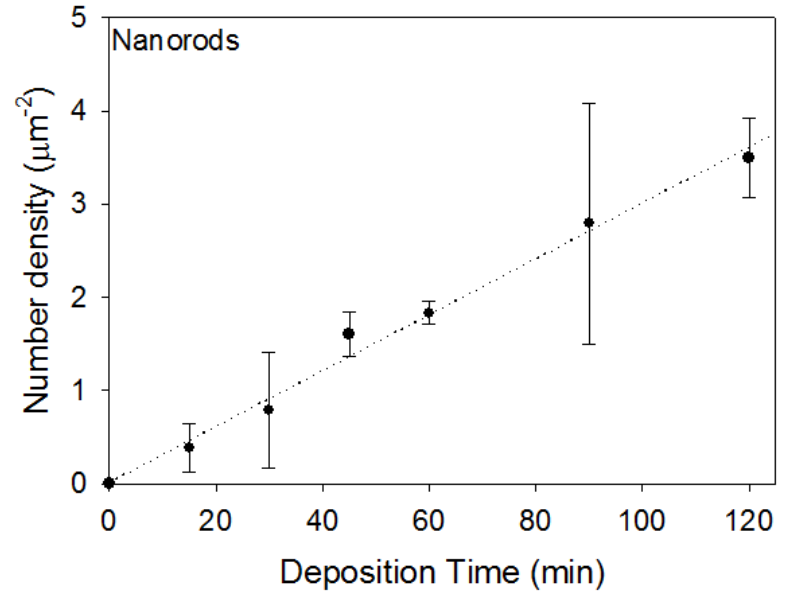

Figure 6

Page 21 

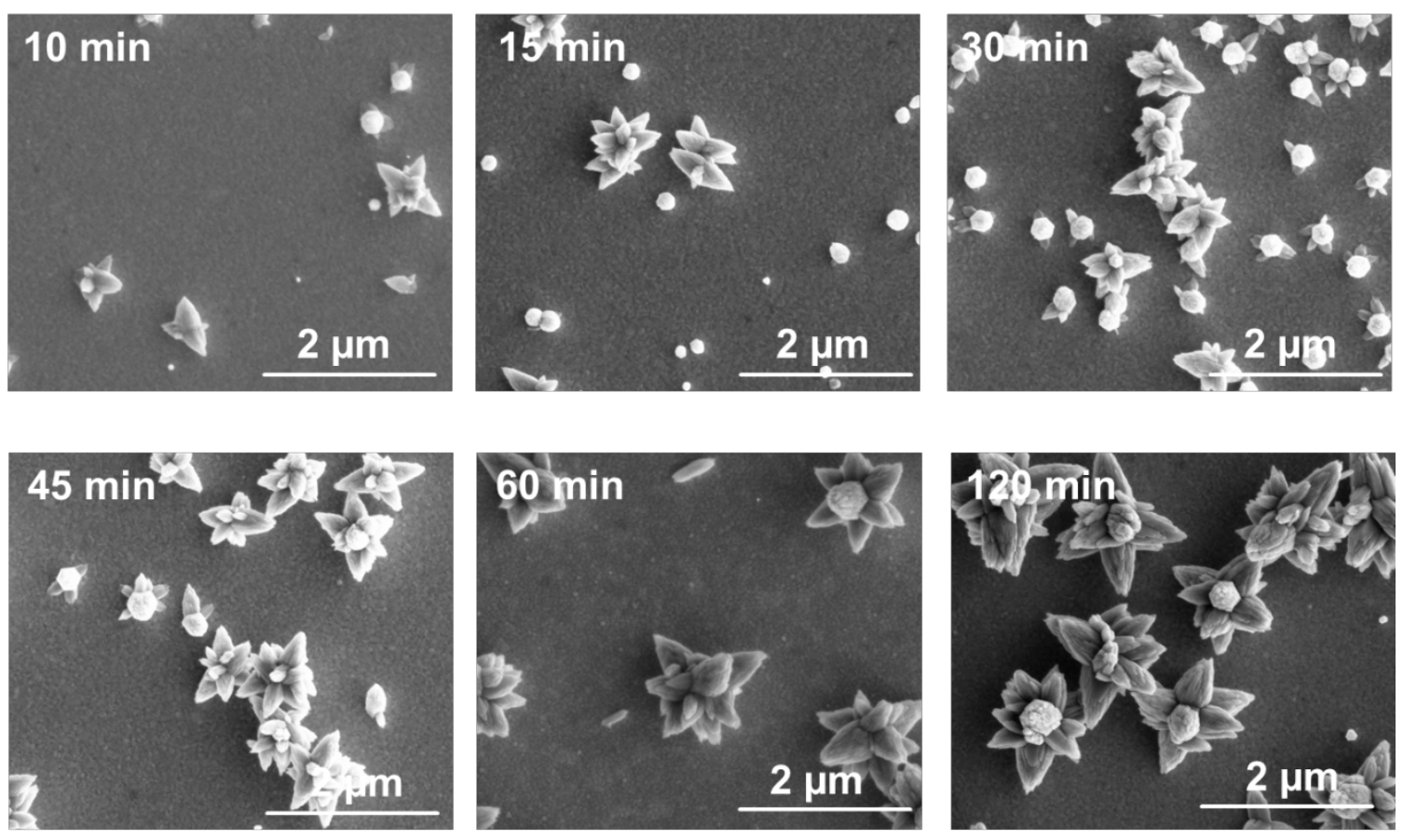

Figure 7 

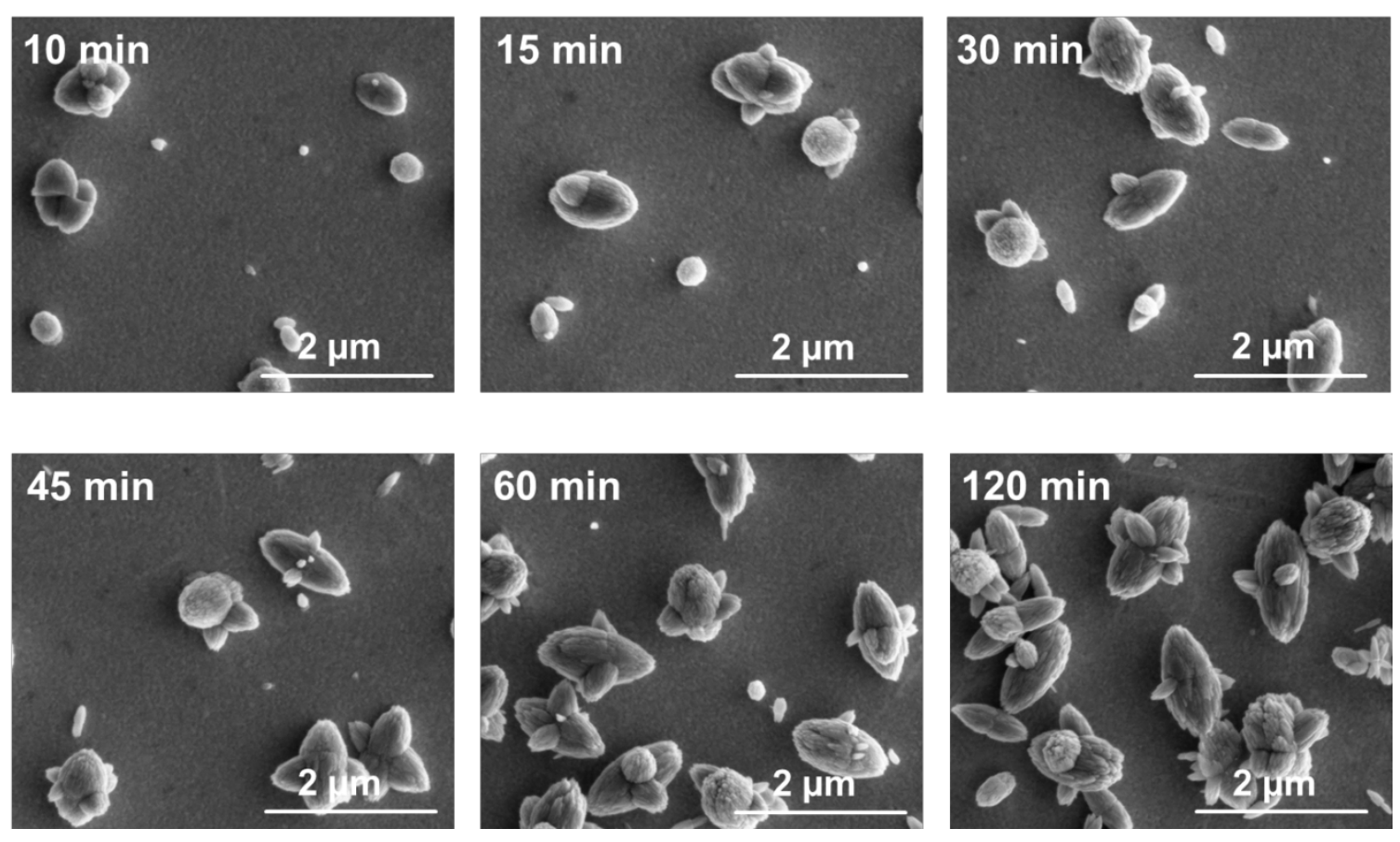

Figure 8 

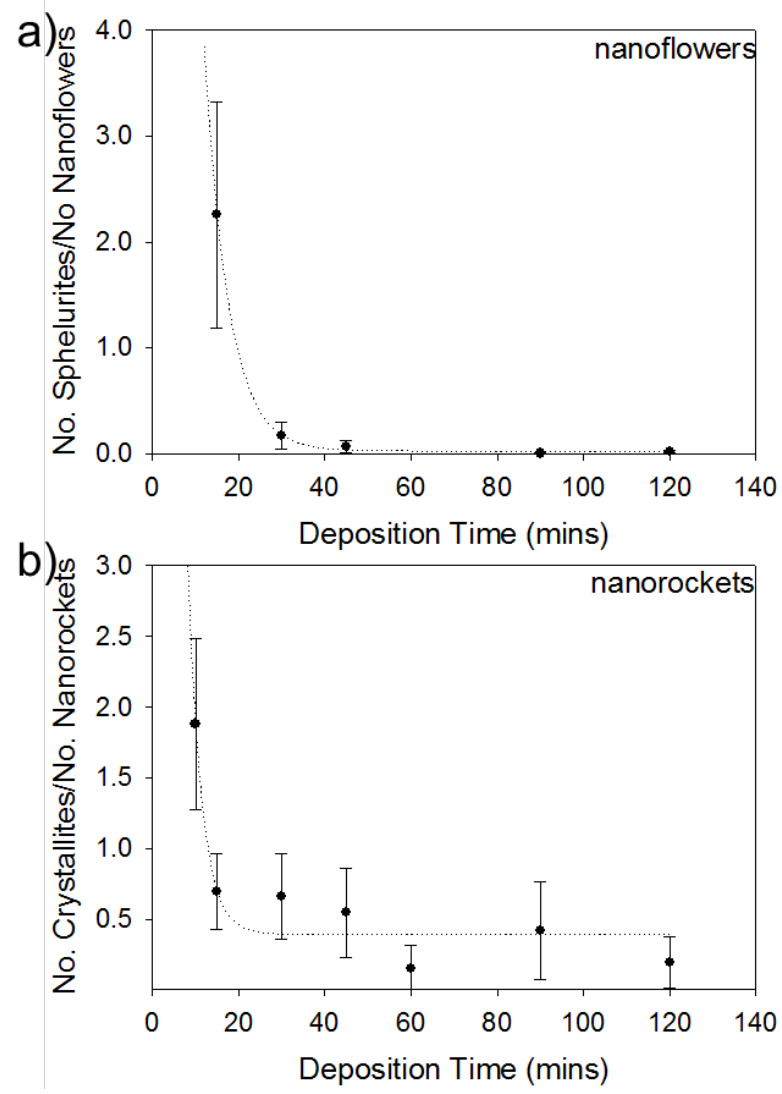

Figure 9 

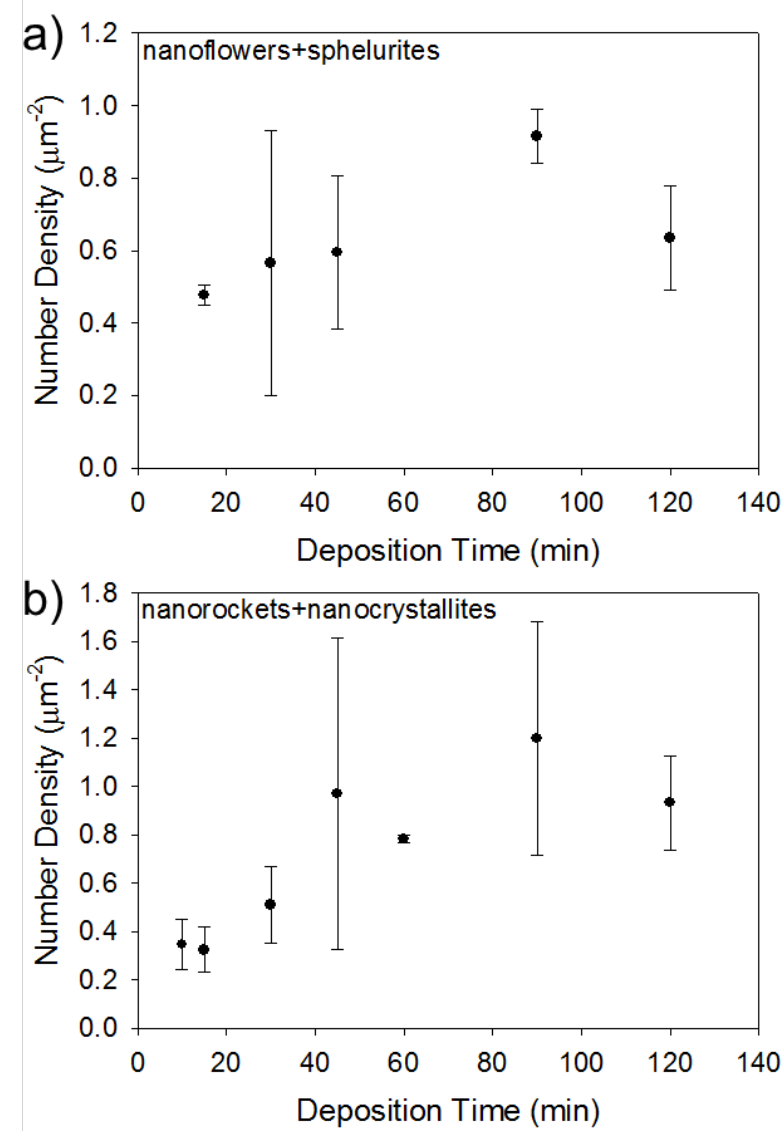

Figure 10 